\title{
面向机器人应用的具有改进效率和可控刚度的 变磁化电机
}

\author{
白坤 ${ }^{1 *}$, 朱朗 ${ }^{1}$, 袁密 ${ }^{1}$, 李国民 ${ }^{1,2 *}$
}

1. 华中科技大学数字制造装备与技术国家重点实验室, 武汉 430074;

2. 佐治亚理工学院机械工程系, 亚特兰大 30332, 美国

*E-mail: kbai@hust.edu.cn; kokmeng.lee@me.gatech.edu doi: 10.1360/SST-2019-0003

电机是机器人的关键驱动组件. 虽然机器人有了 前所未有的机动性、可操作性与人机交互能力，但是 机器人的驱动系统仍然沿用了工业机器人的传统方 案，并在两个方面受到了制约：柔顺性和低速时的效 率. 传统电机为了保持高位置精度，一般具有很高的 刚度, 但是在辅助和康复机器人中需要与人体合适的 刚度. 另外, 传统直流电机在高速时具有很高的效率, 但是在低速或静止状态时的效率非常低. 在机器人应 用中, 驱动系统大部分的运动都是在低速状态下运行 的，这就导致电机总是工作在低速状态下，从而使效 率低下. 利用一种可以实时改变永磁体磁化强度的方 法, 英文全文提出了可以满足机器人应用中对电机效 率和驱动顺应性要求的新型电机. 这种电机有两种不 同的驱动模式: 电磁驱动和可变磁化永磁驱动. 与传 统电机相比, 变磁化电机除了电磁驱动还增加了变磁 化的永磁驱动. 永磁驱动是通过额外的可变磁化强度 的永磁体层实现的. 这种磁体的磁化强度可以在短时 间(微秒级)内通过电流脉冲的磁化连续改变. 由于永 磁体一旦磁化维持转矩不会持续消耗能量, 并且具有 类似于弹簧的刚度特性, 因此永磁体力驱动有助于提 高电机低速时的效率和柔顺性. 论文建立了两种驱动 模式下的电机转矩模型, 实现了电机扭矩与输入的定
量表达. 在研究磁性材料的磁滞特性的基础上, 提出 了一种永磁实时磁化方案, 并建立了利用电流脉冲实 现永磁磁化过程的标准. 最后通过仿真与实验验证了 定量改变永磁磁化强度的可行性并分析了变磁化电机 的功能和性能.

可变磁化强度电机的模型如图1(a)所示. 电机由 转子和定子组成. 转子由永磁体镶嵌组成, 永磁体沿 着径向磁化, 且相邻永磁体的磁化方向相反. 定子由 两层组成, 一层为电磁线圈, 一层为变磁化永磁体. 当 线圈通过电流时, 线圈可以通过洛伦兹力施加扭矩. 变 磁化永磁体由磁化线圈和永磁体组成. 通过控制磁化 线圈的电流脉冲, 可以使嵌入线圈中的永磁体的磁化 强度设置为可磁化范围内的任意值. 在高转速范围, 电机可由电磁驱动模式, 类似传统电机驱动; 在低转 速和静止的情况下, 可通过变磁化永磁模式驱动, 通 过两种驱动模式的交替, 实现电机高效率的驱动.

可变磁化强度电机的相关仿真结果如图1(b)和 (c)所示. 图1(b)表示变磁化永磁体驱动模式下的效率 与线圈驱动时的效率对比，同时也与传统电机的效率 曲线作了比较，其中表示了变磁化永磁体以三种不同 转子增量角度 $\left(\Delta \theta=1^{\circ}, 3^{\circ}, 5^{\circ}\right)$ 磁化时的效率. 从图1(b) 可以看出, 在低速情况下, 可变磁化强度磁体驱动比

英文全文见： Bai K, Zhu L, Yuan M, et al. Design concept development of a variable magnetization motor with improved efficiency and controllable stiffness for robotic applications. Sci China Tech Sci, 2019, 62: 39-46, https://doi.org/10.1007/s11431-018-9406-5 


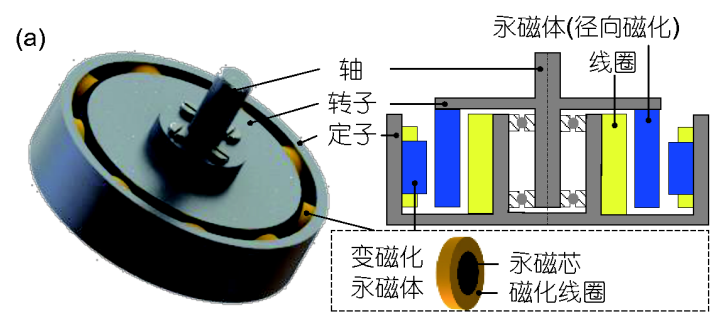

(b)
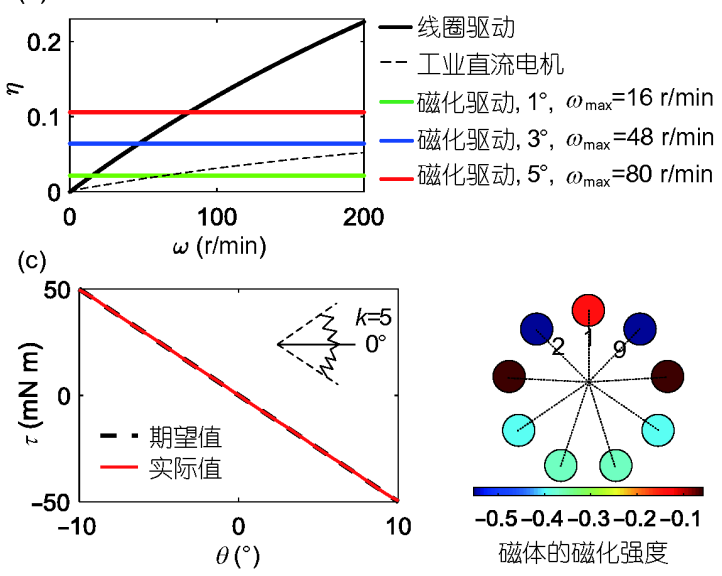

图 1 (网络版彩图)电机的结构及效率和刚度仿真

线圈驱动和传统电机有更高的效率. 图1(c)表示电 机转动位移与转矩的关系, 其中颜色表示每个可变磁 化强度磁体的磁化强度. 与传统电机通过控制改变
刚度不同, 只要可变磁化强度磁体按需要磁化完成, 不需要任何功率输入就能保持类似于弹簧的刚度 特性. 